\title{
A Model to Assess Efficiency in e-Training for Significant Learning (e-TSL)
}

\author{
José Capacho, Ph.D. ${ }^{1}$, Augusto Salazar, M.Sc. ${ }^{1}$, and Miguel Jimeno, Ph.D. ${ }^{1}$ \\ ${ }^{1}$ Universidad del Norte, Colombia, jcapacho@uninorte.edu.co, augustosalazar@uninorte.edu.co, majimeno@uninorte.edu.co
}

\begin{abstract}
This article presents an evaluation model to assess the efficiency of e-Training for Significant Learning (e-TSL). The model is useful for assessing student learning in virtual spaces. The process of model building is based on the Dembo learning teaching model, the systemic approach to evaluate virtual learning from $\mathrm{Dr}$. Khan, and a cybernetic model to evaluate virtual learning environments. This model was built considering the theories of Computer Science and Education Science and its structure is composed of 6 dimensions, 32 characteristics, 84 variables and 153 indicators. The validation of the model was done internationally with participants from Europe, America, Australia, Asia and Africa achieving a total of 1,207 responses, for which the multilingual system (English-Spanish) SIDEC was built. Taking into account the collected responses and with a confidence level of $90 \%$, the components of the e-TSL model were accepted.
\end{abstract}

Keywords-Virtual Education, ICT, Significant Learning.

\section{INTRODUCTION}

The importance and expansion of training processes in virtual spaces supported by ICT, creates the necessity of assuring the educational quality in eLearning. Therefore, the eTSL model presented here is a research work that, through a set of indicators, ensures the quality of the eLearning training process. The importance of building the model for e-TSL is based in the fact that within the evaluation component of the general model of strategic planning, the evaluation relates the operational part of the assessment with the part of evaluation management. This management is represented by the information system build to have a management system for virtual learning - (SIGAVI for its initials in Spanish).

The model for e-TSL is structured into the following sections: i) Architecture construction, with its analysis, the definition, and analysis of functional relationships that make up the model (base model categories e-TSL, and its components: dimensions, characteristics, variables and indicators). ii) Development of the model dimensions that are: identification, academic, pedagogical-didactic, formative, evaluative and technology, iii) Validation of the model. iv) Design and implementation of an information system for the model that evaluates e-TSL. V) Finally, we present a section on conclusions and future work.

The contributions of this work are: i) the model that takes into account the learning process eLearning of the student. ii) Validation of the model in an international setup. iii) The International Standards in eLearning (IMS-LOM) that are taken into account for the model.

Digital Object Identifier (DOI): http://dx.doi.org/10.18687/LACCEI2018.1.1.415 ISBN: 978-0-9993443-1-6 ISSN: $2414-6390$

\section{BACKGROUND}

The support of the e-TSL model is the theory of education applied to the assessment of learning in e-Learning and Information Technology in using platforms applied to the evaluation of learning with ICT. The assessment of learning in e-Learning is divided into 1) Ensuring the quality of eLearning. 2) Performing the assessment of students. 3) Ensuring the quality of the contents. 4) Evaluating the platform.

E-Learning quality is ensured through: i) Accreditation processes as the authors of [1] state in their book. According to the authors, the accreditation process has become a popular tool for performance evaluation. The endorsement of the certifications, as explained in by [2]: "Accreditation and certification Approaches (for example, from the ZFU, Being the State Office for Distance Learning in Germany), in which providers of e-learning must submit to one-time or regularly audits and are then awarded a certificate." ii) Applying the concept of best practices by the fact that students "... also described feeling secure with the e-learning because the content was referenced. This increased their confidence in relation to knowledge of best practice whilst in placement." [3]. iii) Ensuring the quality of courses based on algorithmic systems such as the "Combination of machine learning algorithms for recommendation of courses in E-Learning System based on historical data" [4]. iv) Using performance measures (Benchmarking) in e-Learning to recommend learning materials represented by "Evaluating collaborative filtering Recommendations inside large learning object repositories" [5]. v) Based on the analysis of the publications in a time series from the year 2000 to 2017,112 publications related to the quality of online education were analysed. The study shows that the factors of online education focus on resources, inputs and the process. However, there is a loss of evidence of the learning of students in eLearning that are verified by quality indicators [6]. vi) With the purpose of building a model for sustainable evaluation in learning processes in virtual spaces supported by ICT, the study was based on structured interviews. The empirical research was based on identifying the essential characteristics in eLearning. This study resulted in little attention in the quality control of eLearning tools [7].

Assessment of e-Learners is represented by i) Assessment Frameworks such as the framework for e-learning presented in [8], or the conversational framework presented in [9], ii) Selfevaluation processes that improve student learning in which

$16^{\text {th }}$ LACCEI International Multi-Conference for Engineering, Education, and Technology: "Innovation in Education and Inclusion", 19-21 July 2018, Lima, Peru. 
"The integration of self-assessment and feedback in the software also stimulates the learners" [10]. iii) Control actions between formal and informal learning that is: "A desirable aim is that learning processes are under the control of the learner, which requires integration of informal learning with formal approaches balancing personal inquiry and coordination with the need for institutional accreditation of evidence of competency." [11]. iv) Rubrics for assessment with which you can judge the performance of students in active learning as in the case of "internal monitoring Teaching through active learning" [12]. v) Actions to build Web 2.0 tools, blogs in which students "...were informed that their blogs and responses to questionnaire items would not only be used for assessment and evaluation purposes at the course and school levels but might also be used for publication and knowledge sharing purposes." [13], and wikis in active learning, such as “... a wiki for collaboratively writing the project documentation ..." [14]. vi) Analysis of student behaviour about video lectures. This behaviour is analyzed by checking the results of the data using algorithms supported by machine learning [15]. vii) Identification of relevant topics in eLearning through the application of group analysis methods and burst detection to identify trends related to student learning and assessment [16].

Curriculum Quality Assurance, courses and contents, are represented by: i) Criteria, models and checklists such as: "A practical set of criteria assessing quality in curricula and in courses is identified, a list of assessment exercises that have been performed so far is provided, and assessment of academic performance and suggestions for future improvements are given" [17]; "E-learning and the science of instruction: Proven guidelines for Consumers and designers of multimedia learning" [18]; "The proposed E-Learning Evaluation Checklist has proven to be a useful and effective tool that can help guide professional evaluators" [19]. ii) Using Feedback from students in terms of monitoring to meet the "process of submitting work for feedback and for formal" [20]; ensuring the learning process of students with system such as the "classroom response system (CRS) that provides instantaneous feedback to teachers and pupils about each pupil's understanding of the concepts just taught." [21]. Research related to the structural requirements of a learning environment supported by ICT. The result is the creation of collaborative virtual learning platforms, taking into account the organizational capacities, resources, service facilities, personal skills of teachers and students, the motivating factors of the virtual collective, and the factors that define the networks social. The research is synthesized in a framework to assess the co-creation of virtual environments [22]. The Frameworks to evaluate Programs and Virtual Courses in order to achieve the effectiveness and quality of education is composed of seven indicators. The essential phases covered by the indicators are the implementation, effectiveness and quality of eLearning. Indicators that are institutional, technological,
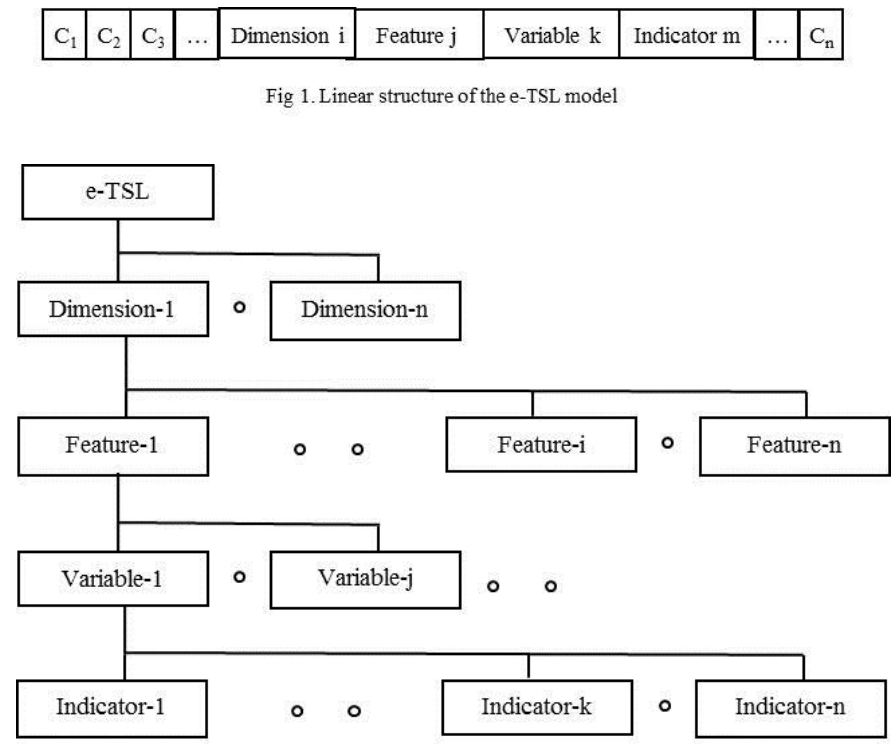

Fig. 2. Tree relationship of the components of the e-TSL model

design courses, learning supports, effectiveness of learning, evaluation of the faculty and finally assessment of student learning [23]. The "Indicators of Engaged Learning Online (IELO)" are represented by the categories of: Instructional Approach, Teaching and Learning. The commitment indices for online learning are represented by the categories of: Instructional Approach, Teaching and Learning. In the IELO indicators, both the design of the course and the teaching are important [24].

4) Assessing platforms support virtual learning with ICT through: i) Flexible platforms with adaptive services represented by works such as "The TKB is a context-informed adaptive service suite" [25] or a technical knowledge base (Technical knowledge base - TKB). ii) Models that ensure the characteristics of e-Learning products such as the Kano Model in "How to build an e-learning product: Factors for student / customer satisfaction" [26]. iii) Quality labels such as QSEL (Qualitätssiegel e-learning) proposed in [27]. iv) Agencies for quality in virtual education. One example is the European Foundation for Quality in E-Learning. They built for this purpose the UNIQUe certification system and launched an eLearning quality label for adoption of ICT use in higher education [28]. v) Evaluation of Learning Management Systems - LMS in terms of functionalities, characteristics and evaluation results in order to guarantee the quality of the virtual classes for the use of GSuite, emphasizing the usability of the platform [29]. Taking into account the change of the eLearning platform, LeaderTIC is a system of recommendations based on a comparative study of free platforms of online education supported by ICT. The LeaderTIC system was implemented in order to facilitate the selection of platforms based on the benefits and potential of pedagogy and technology [30]. 


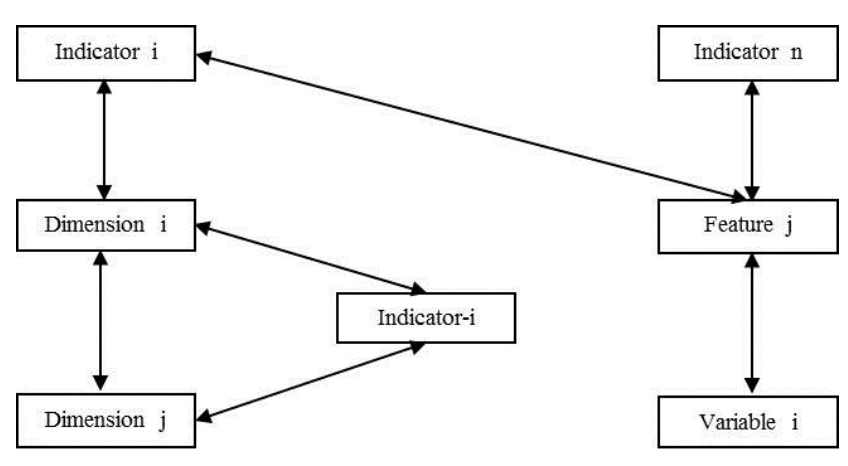

Fig. 3. Network structure of the relationships for the e-TSL model

\section{DEFINITION Of THE E-TSL MODEL}

The architecture e-TSL model has two conceptual bases that are the educational foundation and computer basis. The educational foundation is supported by the documental base previously explained and specifically the representative model of the training process in virtual spaces (Figure 6). This model was built based on: i) Teaching-Learning Model [31] ii) The systemic approach to assessing learning in the virtual student, by Dr. Badrul H. Khan [32]. iii) The Cybernetic model to evaluate virtual learning environments [33] supplemented with concepts of frames "Britain and Liber's Framework" [33] or "The Laurillard Conversational Framework" [34].

\section{A. Functional Structures for the Model Architecture}

To define the characteristics and components of e-TSL, it is necessary to first determine the functional structures that model in an appropriate manner the relationships between its components. The functional structures to analyze are three: linear, tree, and network:

- Linear functional structure (Figure 1), represented by its elements enclosed in parentheses and separated by commas as follows $\left(E_{1}, E_{2} \ldots E_{n}\right)$, where $E_{i ' s}$ are the elements of the list [35]

- Functional Tree structure is based on the Data Model Tree [35], in which the information is represented in the form of an inverted tree which has a relationship similar to that found in a hierarchical order in a family tree (Grandfather $\rightarrow$ father $\rightarrow$ son $\rightarrow$ grandson ...) (Figure 2).

- Functional network structure, based on Graph Data Model defined as a binary relation [35] between a set of points called nodes which are connected by a set of lines called arcs. (Figure 3).

\section{B. Analysis and selection of the functional structural base}

The functional structures supporting the e-TSL model will be assessed and selected according to three characteristics of analysis which are: relationships, conditions of contradiction and phenomenon modeling.
Relationships are divided into three: linear, hierarchical and by content relationships.

- Linear Relationships: The three structures: linear, tree and network relationships meet linearity which implies that within its components, set order relations can be denoted by predecessor, current and successor.

- Hierarchical Relationships: The only functional structure that conforms to hierarchy model relationships is the tree, which means that the components of the e-TSL model can be organized into a structure of family order (grandparentchild-grandchild), constituting an inverted structure tree with e-TSL as root. It is composed of a set of ndimensions; these are represented by a set of features and these, in turn, contain within the variables and indicators for the analysis feature. Then, the value judgment of each of the indicators for each feature, and the value judgments of the characteristics of the dimension, given the value judgment of the dimension. Finally, binding of the value judgments of the dimensions give the final judgment of value of real e-TSL, or equivalently, the value judgment of student learning by interacting with a platform for tele training.

- Content Relationships: The only structure that meets with content relationship is the hierarchical structure. The content relationship in the e-TSL model for the functional tree structure is applied. From simple to complex, the model has the following components: Indicators (I) and Variables $(\mathrm{V})$ are contained in the Features (R). These (R) features are contained in the Dimensions (D), the Dimensions are finally a subset of e-TSL model. The model can be written mathematically as $(((, \mathrm{I}, \mathrm{V}) \subset \mathrm{R}) \subset$ D ) $\subset$ e-TSL ).

\section{Analysis of Contradictory Conditions}

Contradictory conditions are those functional structures that validate the consistency of the functional support structure for the e-TSL model, and therefore allow the selection of the most appropriate structure to model the phenomenon under study.

The proposed categories in the e-TSL model are not linear, given the hierarchical relationship. There are two fundamental contradictions when selecting the linear structure: first, they are not hierarchical; and second, they do not allow the classification of homogeneous groups of variables and indicators belonging to a property as a basis for evaluating a dimension.

The hierarchical relationship is also not modeled by the functional network structure. This structure has the ability to allow multiple relationships among its components. It thus makes everyone related to everyone, regardless of the significance of the relationship. This structure implies that you can connect multi-level relationships between categories of the same species to achieve the evaluation as shown in Figure 3. In

$16^{\text {th }}$ LACCEI International Multi-Conference for Engineering, Education, and Technology: "Innovation in Education and Inclusion", 19-21 July 2018, Lima, Peru. 


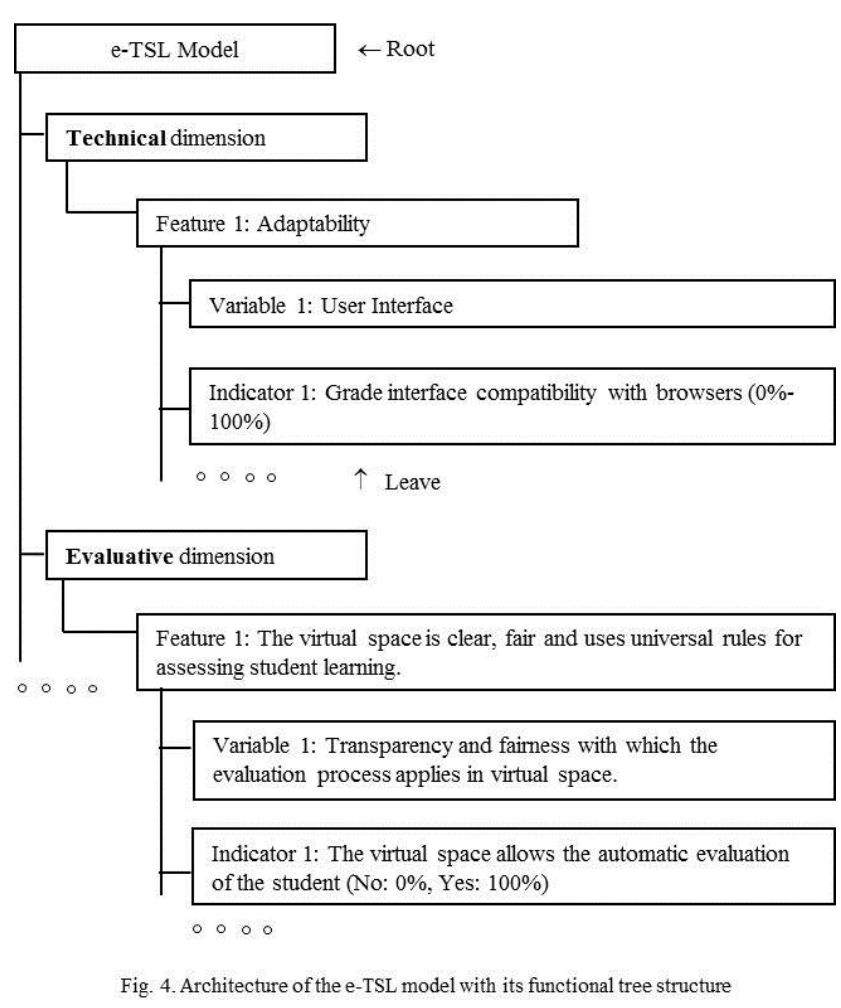

this case, an indicator of the e-TSL model belonging to a dimension Di would be related to another indicator belonging to the dimension $\mathrm{Dj}$; but since the dimensions $\mathrm{Di}$ and $\mathrm{Dj}$ are different, the indicator may not contribute to the evaluation of two dimensions. Two different dimensions, technological (D1) and pedagogical (D2), and an indicator (I) to technically evaluate the data transmission speed between the server and the client in a virtual environment (I1) are defined. Then I1 is used to assess D1. But the assessment of D2 through I1 is not logical or consistent.

We can qualitatively conclude that the "the functional structure tree" is the one that models the case study the best. This statement is based on the following reasons: the linear and network structures present contradiction conditions; the tree structure meets the linearity, hierarchical, and content relationships; and further, no contradictions arise within the structure as a basis for the e-TSL model.

\section{Modeling Analysis of the Educational Phenomenon}

The modeling of the phenomenon, or educational situation presented in a training process supported by virtual environments, is the way the functional structure represents the interrelationship between students' knowledge structures and the environment virtual.

The virtual environment consists of a set of frames (windows). They have a pedagogical approach and learning objectives. The frames are related to one or more areas of knowledge forming contents that are located in the domain of image, audio, and touch. The organizational structure of the set of frames within the virtual environment is a typical network structure.

On the other hand, we have the relationship between the real world when being represented in a virtual space and the subject's thought structures mediated by symbolic language forms a generic network structure. Then the student's learning when using eLearning tools is a virtual learning system with a typical network structure.

The processes used in the environment of virtual training and student learning by interacting with the computer are based on typical network structures. It can then be concluded that the functional structure that best models the phenomenon or educational situation subject-object in eLearning platforms is the network structure.

This implies that the functional network structure models the subject-object phenomenon of knowledge-computer. The selection of functional network structure to assess student learning in virtual training processes is considered the best way to represent the educational phenomenon in question. However, there is a structural contradiction if one takes into account that the network structure functional does not model hierarchical relationships as demonstrated in the previous section. Having discarded the network structure, the question is whether the base functional structure for representing the educational phenomenon in a virtual environment would be hierarchical or not.

Based on the virtual training platform, the frames set within the typical network structure can be structured in a hierarchical manner, which is justified as follows. First, the virtual course, whatever the platform used, must have an entry point; said entry point is the tree root of the virtual course. Secondly, starting from the root, regardless of the course structure, navigation within the virtual environment leads students to a set of content; and content, navigation action can be modeled by a tree structure. Clearly the student will never acquire the content of the course or all the learning from the course content, if it is based on a single navigation action. Therefore, a tree representation of the virtual environment system is feasible.

The student learning system is analyzed when it interacts with the virtual environment. Here, learning is evaluated through a set of dimensions, which in turn contain features and these contain variables and indicators. The model works collecting the information from indicators, assessing the characteristics and from these characteristics the dimensions are assessed. This is equivalent to traversing the tree of the eTSL model. The tree is traversed from leaves to root and it is integrally evaluating student learning. This action is implicitly evaluating the "learning network" of the student. Then, assessment of student learning in their relationship with a virtual training platform is a system that can be modeled using tree structures to assess student learning.

Therefore, the virtual environment system and the system for assessing student learning can be modeled quantitatively in

$16^{\text {th }}$ LACCEI International Multi-Conference for Engineering, Education, and Technology: "Innovation in Education and 
TABLE I

ANALYSIS AND SELECTION OF THE BASE STRUCTURE FOR REPRESENTING THE ARCHITECTURE OF THE E-TSL MODEL

\begin{tabular}{|c|c|c|c|c|c|c|c|}
\hline \multirow{3}{*}{$\begin{array}{l}\text { Functional } \\
\text { Structures }\end{array}$} & \multicolumn{5}{|c|}{ Characteristics Analysis of the Functional Structure Selection } & \multicolumn{2}{|c|}{ Selection } \\
\hline & \multicolumn{3}{|l|}{ Relations } & \multirow{2}{*}{$\begin{array}{c}\text { Contradictory } \\
\text { conditions }\end{array}$} & \multirow{2}{*}{$\begin{array}{c}\text { Phenomenon } \\
\text { Modeling } \\
(0-100)\end{array}$} & \multirow{2}{*}{ Qual. } & \multirow{2}{*}{ Quant. } \\
\hline & Linearity & Hierarchical & Content & & & & \\
\hline Linear & Yes & No & No & Yes & 20 & $\mathrm{NO}$ & 20 \\
\hline Tree & Yes & Yes & Yes & No & 80 & Yes & 80 \\
\hline
\end{tabular}
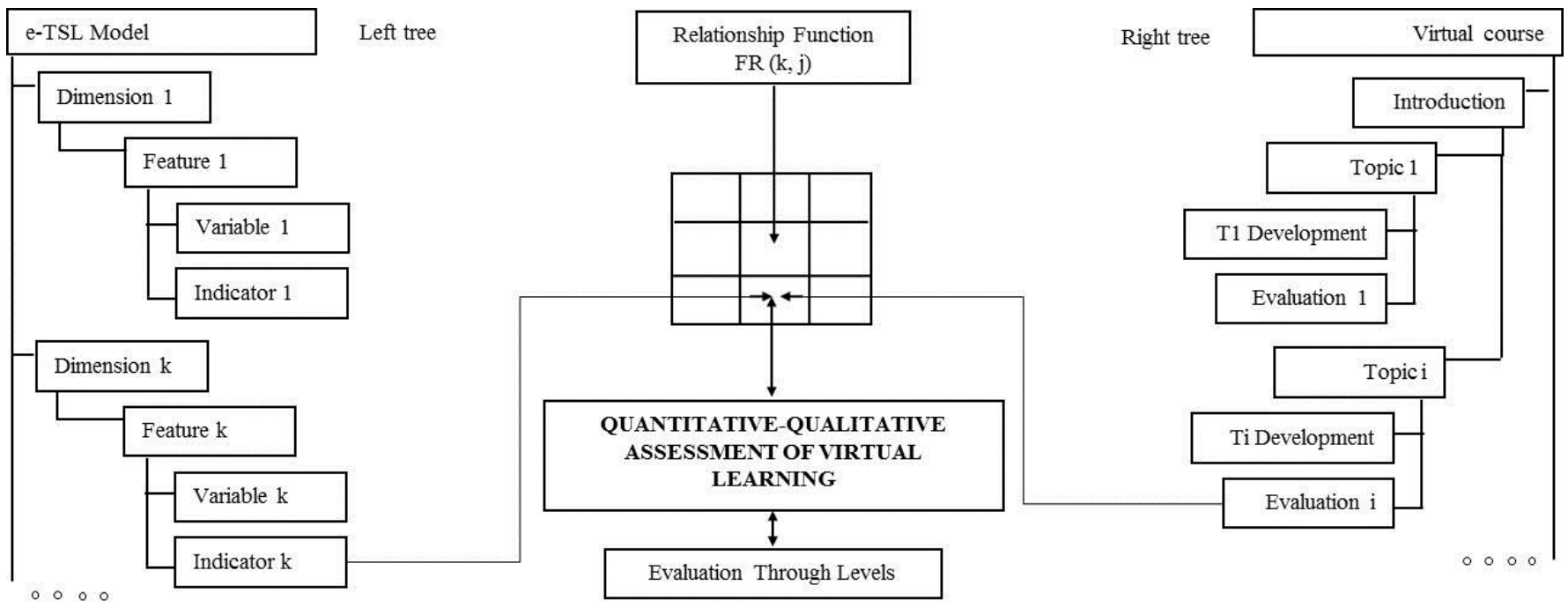

Fig. 5. Interrelation of the e-TSL model with the virtual course organization

an estimate of $80 \%$ with tree functional structures. The chart analysis and selection of the base structure for representing the functional architecture of the e-TSL model are shown in Table I. In conclusion the selected functional structure for the architecture of the e-TSL model is the tree. It is justified because in the tree structure, the linearity, hierarchical and content relations are presented. There are no contradictions in this structure to achieve the representation of the student learning assessment in a situation of virtual training; and the quantitative representation of the analyzed phenomenon or educational situation is about $80 \%$. Once the architecture of the model is selected and justified, the next step is to define the components of the model.

\section{ARCHITECTURE Of THE E-TSL MOdeL}

Considering the functional structure above justified as a basis for building e-TSL, the model is structured as a hierarchical inverted tree, with the label or identification of the e-TSL model as root, from which dimensions emerge (children of e-TSL) as general functional units to assess student learning. Dimensions, in the hierarchical structure of the model, are composed of features (grandchildren of e-TSL), and these in turn have as children variables and indicators (grand-grandchildren of e-TSL). Those become specific units essential to assess student learning in the process of virtual learning (Figure 4):

A. Analysis and selection of the functional structural base

The student in its learning process interacts with a virtual platform. Then from the architecture of the e-TSL model, you should relate the components of the model with the constituent parts of the virtual course. As was stated in the modeling of the phenomenon, two systems interact with each other. The two interacting systems are: the student learning evaluation system and the virtual platform. Both systems have the characteristic of having tree structures; in this sense they are compatible for interrelation, comparison and evaluation processes. Then two tree structures to be compared are generated, arranged as follows: the structure of "left tree" represents the evaluation system of student learning in virtual environments or e-TSL model; while the structure of "right tree" represents the organizational system of the virtual course.

The two systems will interrelate throughout Relationship Functions (RF). These functions will allow contrasting the components of the e-TSL model with the virtual course presented by the teacher. Therefore the relational functions evaluate this interrelation either at a quantitative or qualitative scale, where the assessment of student learning is obtained. The interrelation between the e-TSL model (left tree) and the

$16^{\text {th }}$ LACCEI International Multi-Conference for Engineering, Education, and Technology: "Innovation in Education and Inclusion”, 19-21 July 2018, Lima, Peru. 


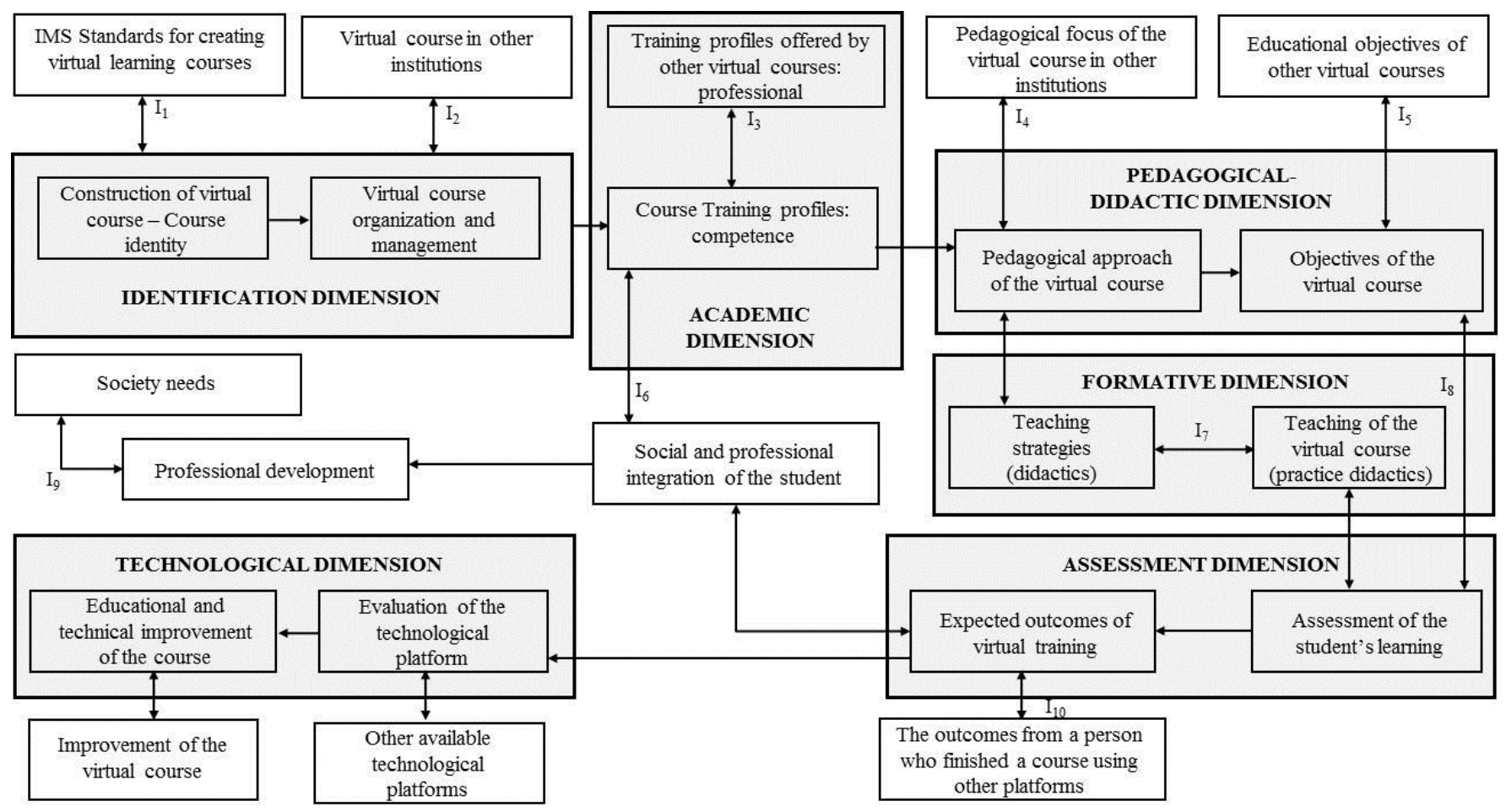

Fig. 6. Components of the e-TSL Model

organization of the virtual environment (right tree) is shown in Figure 5.

The Relationship Function RF $(k, j)$ is responsible for assessing the state of the $\mathrm{k}$ component of the e-TSL model, compared to what was presented by the virtual course or executed by the student, corresponding to the component $j$ of the virtual course.

\section{B. Construction of the categories in the e-TSL Model}

In the construction of the content categories of the e-TSL model, the following is taken into account:

- The model representative of the training process in virtual spaces.

- The dimensions that comprise the educational phenomenon or situation of student learning in the virtual environment, which are defined within the representative model of the formation in virtual spaces.

- The functional model tree structure, represented by dimensions, characteristics, variables and indicators.

The dimensions defined, being systemic components of the online learning process, evaluate through indicators the learning achieved by the student while interacting with the etraining platform. The dimensions that will be considered in the model are:

- Identification dimension

- Academic dimension

- Pedagogical-didactic dimension
- Formative Dimension.

- Assessment dimension

- Technology dimension

The main purpose of the e-TSL model is to assess student learning. This requires an identification dimension of the virtual course as a starting point to define the identification of the course. Once the course has been identified is the academic dimension that defines profiles training of students, which are achieved through the pedagogical dimensions that define the pedagogical approach of the model and the didactic, which is responsible for developing the teaching strategies that dictate how to teach.

The didactic pedagogical dimension of the e-TSL model dimension makes possible, within the virtual course, the development of the educational dimension of the students. The above dimensions require an evaluative dimension, which is explicitly responsible for assessing student learning in training processes in virtual spaces. Finally, all the above dimensions required for operation of a technological dimension, which contains the features related to technology hardware, software and communications on which the virtual learning environment with ICT work.

The dimensions of identification, academic, pedagogicaldidactic, formative, evaluative and technological of the e-TSL model are shown graphically in Figure 6. 
TABLE II

RESUlTS OF THE COMPUTER-BASED VALIDATION OF THE E-TSL MODEL

\begin{tabular}{|l|l|c|c|c|c|c|c|c|c|c|}
\hline & Dimension & NE & NI & NE*NI & TA & PA & NN & PD & TD & Total \\
\hline 1. & Identification & 13 & 14 & 182 & 110 & 36 & 15 & 13 & 8 & 182 \\
\hline 2. & Academic & 9 & 25 & 225 & 130 & 51 & 17 & 9 & 18 & 225 \\
\hline 3. & Pedagogical-Didactic & 12 & 8 & 96 & 63 & 27 & 2 & 0 & 4 & 96 \\
\hline 4. & Formative & 8 & 32 & 256 & 131 & 78 & 16 & 10 & 21 & 256 \\
\hline 5. & Evaluative & 8 & 38 & 304 & 172 & 87 & 16 & 3 & 26 & 304 \\
\hline 6. & Technological & 4 & 36 & 144 & 85 & 17 & 18 & 1 & 23 & 144 \\
\hline & Total & 54 & 153 & 1207 & 691 & 296 & 84 & 36 & 100 & 1,207 \\
\hline & \multicolumn{7}{|c|}{ TA: Strongly agree } \\
\hline
\end{tabular}
NE: Number of answered surveys
NI: Number of indicators
NE*NI: Total answers for dimension

Percentage of answers for the validation of the e-TSL model, relative to the number of indicators for each dimension.

\begin{tabular}{|l|l|c|c|c|c|c|c|c|c|c|}
\hline & Dimension & NE & NI & NE*NI & TA & PA & NN & PD & TD & Total \\
\hline 1. & Identification & 13 & 14 & 182 & $60.44 \%$ & $19.78 \%$ & $8.24 \%$ & $7.14 \%$ & $4.40 \%$ & $100,00 \%$ \\
\hline 2. & Academic & 9 & 25 & 225 & $57.78 \%$ & $22.67 \%$ & $7.56 \%$ & $4.00 \%$ & $8.00 \%$ & $100,00 \%$ \\
\hline 3. & Pedagogical-Didactic & 12 & 8 & 96 & $65.63 \%$ & $28.13 \%$ & $2.08 \%$ & $0.00 \%$ & $4.17 \%$ & $100,00 \%$ \\
\hline 4. & Formative & 8 & 32 & 256 & $51.17 \%$ & $30.47 \%$ & $6.25 \%$ & $3.91 \%$ & $8.20 \%$ & $100,00 \%$ \\
\hline 5. & Evaluative & 8 & 38 & 304 & $56.58 \%$ & $28.62 \%$ & $5.26 \%$ & $0.99 \%$ & $8.55 \%$ & $100,00 \%$ \\
\hline 6. & Technological & 4 & 36 & 144 & $59.03 \%$ & $11.81 \%$ & $12.50 \%$ & $0.69 \%$ & $15.97 \%$ & $100,00 \%$ \\
\hline
\end{tabular}

\section{VALIDATION OF THE MODEL}

The e-TSL model is validated using the Distributed Computer System Evaluation Survey - SIDEC. The SIDEC system (Capacho, R., Monroy, G. Sanchez, G., 2005) is a system developed in ASP, Flash MX and ActionScript 2.0 that uses the MySQL database. The system works between the server where the system is stored and the client's computer; passes through a firewall to provide security to both the system where the control logic of the SIDEC is and the database where are stored the answers for the validation of the e-TSL. SIDEC supports both, Spanish and English languages. The system was implemented in Europe and Latin America to validate the e-TSL model.

To validate the e-TSL model using SIDEC the initial population was distributed as follows: one hundred and twelve (112) from the European Union, one hundred (100) from America (80 from South America and 20 from North America), six (6) from Australia and finally one (1) from Asia and one (1) from Africa. From the contacted persons (220), a final 100 people answered the survey.

Considering that the model has 153 indicators, 84 variables and 32 characteristics, logistically it was impossible for each person to solve all indicators. Therefore, surveys were deployed assigning to each person one or more dimension depending on their profile. Of the total population, $34 \%$ responded to the survey for a total of 54 filled surveys and
1,207 online responses using the SIDEC computer system. Table II shows the results of the validation of the e-TSL model.

The validation of the e-TSL model was performed through the Distributed Computer System Evaluation Survey (SIDEC), taking into account all indicators show the following results. Of the 1,207 responses, the 57.25\% (691 responses) correspond to strongly agree and $24.52 \%$ (296 responses) correspond to partially agree, which would give a trend of $81.77 \%$ on the scales partially and fully agree; these values contrast with the results in the range $2.98 \%$ partially disagree and strongly disagree $8.29 \%$, for an overall total of $11.27 \%$ for scales somewhat disagree and strongly disagree.

A. Analysis of the computerized model validation of e-TSL

The computerized validation recorded a total of 54 surveys. Since the number of surveys is greater than 30 , and assuming that the survey results follow a normal statistical distribution, using a confidence level of $90 \%$ and $10 \%$ error, it can be said that:

$$
Z_{x}=\left(X-\mu_{X}\right) / \sigma_{X}
$$

Then $\mathrm{Z}_{0.95}=1,645$ and $\mathrm{Z}_{0.05}=-1,645$ (1)

16 ${ }^{\text {th }}$ LACCEI International Multi-Conference for Engineering, Education, and Technology: "Innovation in Education and Inclusion", 19-21 July 2018, Lima, Peru. 
TABLE III

SUMMARY OF THE COMPONENTS OF THE E-TSL MODEL

\begin{tabular}{|c|c|c|c|c|}
\hline & \multicolumn{5}{|c|}{ Model Components } \\
\hline No. & Dimensions & Features & Variables & Indicators \\
\hline 1. & Identification & 4 & 5 & 14 \\
\hline 2. & Academy & 4 & 20 & 25 \\
\hline 3. & Pedagogical-didactic & 2 & 6 & 8 \\
\hline 4. & Formative & 8 & 18 & $\underline{32(3)}$ \\
\hline 5. & Evaluative & 6 & 18 & $\underline{38(1)}$ \\
\hline 6. & Technological & 8 & 17 & $\underline{36(2)}$ \\
\hline Total & & 32 & 84 & 153 \\
\hline
\end{tabular}

For purposes of conducting a hypothesis test for statistical $\mathrm{P}$, defined $\mathrm{P}=$ the proportion of respondents who are not in disagreement, then the acceptance region is delimited by $1.645<\mathrm{Zp}>1.645$; and the rejection region, $Z_{\mathrm{p}}<-1.645$ and $Z_{p}>1.645$.

Based on the sample evidence, if the calculation of the statistical distribution $\mathrm{P}$ is performed, then:

$$
Z_{p}=\left(P-\mu_{p}\right) / \sigma_{p}
$$

finding the value of $\mathrm{P}$ :

$$
P=\left(Z_{p}^{*} \sigma_{p}\right)+\mu_{p}
$$

the calculated values for the model validation with a sample size of $\mathrm{n}=54$ by applying the computerized survey:

$$
\mathrm{P}_{\text {Computerized }}=(1.17 * 1.645)+89.9027=91.83
$$

As the calculated statistical value falls within the acceptance region, it is concluded that based on the sample evidence the initial hypothesis $\mathrm{P}=0.9$ is accepted, justified by the confidence level selected initially.

Given the fact that statistical validation of the e-TSL is reliable, which means that all the indicators of the evaluation model to access the efficiency for the e-Training for Significant Leaning e-TSL are accepted. It is important to note that the total percentage of agreement via the computerized survey reached a value of $81.77 \%$, the percentage of respondents who were neither agree nor disagree is $6.96 \%$, and finally the total registered disagreement was $11.27 \%$.

\section{CONCLUSIONS}

After the design, validation and digitalization of the model for online learning significant formation e-TSL, it is concluded: First, the fundamental contributions in terms of software development are:

The design, development, coding and testing of the components of the Evaluator system of Learning with Virtual Spaces - SEAVE and the Distributed Computer System Evaluation Survey - SIDEC were done; the first one represents the computerized version of the e-TSL model, the second one was for the computerized validation of the model.

The e-TSL model was validated and with the help of SIDEC, it was statistically demonstrated that the validation of the e-TSL is trustable, with a result of an $81.77 \%$ of the subjects answered totally agree or partially agree.

Second, the structural results in terms of research are:

The structure of the e-TSL model and the contents of its components on terms of dimensions, characteristics, variables and indicator, as they were designed, do not exist on the same form for the process of construction of virtual spaced supported by ICT.

The architecture of the e-TSL model and the idea behind its relationship between the model and the structure of the virtual course using the function of relationship is owned by the authors of the present research, and as such, the idea is original and does not exist on Spanish or English literature. Then, it is emphasized that the construction of the architecture of the model e-TSL was based on the analysis of three functional structures, linear, tree and network, evaluated each according linear and hierarchical relations, content, conditions contradiction and modeling the phenomenon, concluding that the best basic functional structure architecture to e-TSL model is the tree. The tree structure allows, within the model, to relate the components of the e-TSL model with parts of the virtual course through functions of relations, which after being evaluated result in the assessment of student learning process in virtual spaces.

Finally, based on the architecture of the e-TSL model, the higher level components or daughters of e-TSL were defined, which are the dimensions of academic, pedagogical-didactic, evaluative and technology identification, taking into account the representative model the process of formation of the student in virtual spaces. For each of the dimensions their respective features, variables, and indicators were built. They total to an amount of 6 dimensions, 32 characteristics, 84 variables and 153 indicators and are shown in Table No. III. Components e-TSL model, where can be observed that the evaluative (1) technological (2) and formative (3) dimensions, have the largest number of indicators, corresponding to the purpose of the model, which is the assessment of student learning in virtual level.

With the design and evaluation of e-TSL model complete, a new goal for research is to integrate the e-TSL model within the System Management of Virtual Learning - SIGAVI.

\section{REFERENCES}

[1] I. Jung and C. Latchem, Quality assurance and accreditation in distance education: Models, policies and research. Routledge, 2012.

[2] U.-D. Ehlers and J. M. Pawlowski, Handbook on quality and standardisation in e-learning. Springer Science \& Business Media, 2006.

[3] J. G. Bloomfield and A. Jones, "Using e-learning to support clinical skills acquisition: Exploring the experiences and perceptions of graduate first-year pre-registration nursing students-A mixed method study," Nurse Educ. Today, vol. 33, no. 12, pp. 1605-1611, 2013.

[4] S. B. Aher and L. M. R. J. Lobo, "Combination of machine learning algorithms for recommendation of courses in E-Learning System

16 $^{\text {th }}$ LACCEI International Multi-Conference for Engineering, Education, and Technology: "Innovation in Education and Inclusion", 19-21 July 2018, Lima, Peru. 
based on historical data," Knowl.-Based Syst., vol. 51, pp. 1-14, Oct. 2013.

[5] C. Cechinel, M.-Án. Sicilia, S. SáNchez-Alonso, and E. GarcíABarriocanal, "Evaluating collaborative filtering recommendations inside large learning object repositories," Inf. Process. Manag., vol. 49 , no. 1, pp. 34-50, 2013.

[6] A. Esfijani, "Measuring Quality in Online Education: A Metasynthesis," Am. J. Distance Educ., pp. 1-17, 2018.

[7] S. Farid, R. Ahmad, M. Alam, A. Akbar, and V. Chang, "A sustainable quality assessment model for the information delivery in E-learning systems," Inf. Discov. Deliv., vol. 46, no. 1, pp. 1-25, 2018.

[8] D. R. Garrison, E-learning in the 21st century: A framework for research and practice. Taylor \& Francis, 2011.

[9] T. Mayes and S. De Freitas, "Review of e-learning theories, frameworks and models," JISC E-Learn. Models Desk Study, no. 1, 2004.

[10] E. Evgeniou and P. Loizou, "The theoretical base of e-learning and its role in surgical education," J. Surg. Educ., vol. 69, no. 5, pp. 665669, 2012.

[11] F. J. García-Peñalvo, M. Johnson, G. R. Alves, M. Minović, and M. Á. Conde-González, "Informal learning recognition through a cloud ecosystem," Future Gener. Comput. Syst., vol. 32, pp. 282-294, 2014.

[12] M. Gainor, D. Bline, and X. Zheng, "Teaching internal control through active learning," J. Account. Educ., vol. 32, no. 2, pp. 200$221,2014$.

[13] G. Osman and J. H. L. Koh, "Understanding management students' reflective practice through blogging," Internet High. Educ., vol. 16, pp. 23-31, 2013.

[14] E. Popescu, "Providing collaborative learning support with social media in an integrated environment," World Wide Web, vol. 17, no. 2, pp. 199-212, 2014.

[15] M. Farhan et al., "IoT-based students interaction framework using attention-scoring assessment in eLearning," Future Gener. Comput. Syst., vol. 79, pp. 909-919, 2018.

[16] S. M. J. Jalali, E. Mahdizadeh, M. R. Mahmoudi, and S. Moro, "Analytical assessment process of e-learning domain research between 1980 and 2014," Int. J. Manag. Educ., vol. 12, no. 1, pp. 4356, 2018.

[17] G. Ahamer, "Quality Assurance in Transnational Education Management: The Developmental "Global," Handb. Res. Transnatl. High. Educ., p. 259, 2013.

[18] R. C. Clark and R. E. Mayer, E-learning and the science of instruction: Proven guidelines for consumers and designers of multimedia learning. John Wiley \& Sons, 2016.

[19] A.-M. Guidy-Oulai and J. M. Tarn, "Organizational e-learning evaluation: The development of a checklist model," Hum. Syst. Manag., vol. 31, no. 3-4, pp. 255-267, 2012.

[20] C. Trevitt, A. Macduff, and A. Steed, "[e] portfolios for learning and as evidence of achievement: Scoping the academic practice development agenda ahead," Internet High. Educ., vol. 20, pp. 69-78, 2014.

[21] M. K. Sheard and B. Chambers, "A case of technology-enhanced formative assessment and achievement in primary grammar: How is quality assurance of formative assessment assured?," Stud. Educ. Eval., vol. 43, pp. 14-23, 2014.

[22] M. Ranjbarfard and M. Heidari Sureshjani, "Offering a framework for value co-creation in virtual academic learning environments," Interact. Technol. Smart Educ., no. just-accepted, pp. 00-00, 2018.

[23] F. Martin and S. Kumar, "Frameworks for Assessing and Evaluating e-Learning Courses and Programs," in Leading and Managing eLearning, Springer, 2018, pp. 271-280.

[24] P. M. Bigatel and S. Edel-Malizia, "Using the 'Indicators of Engaged Learning Online' Framework to Evaluate Online Course Quality," TechTrends, vol. 62, no. 1, pp. 58-70, 2018.
[25] D. Dagger, A. O'Connor, S. Lawless, E. Walsh, and V. P. Wade, "Service-oriented e-learning platforms: From monolithic systems to flexible services," IEEE Internet Comput., vol. 11, no. 3, 2007.

[26] G. Dominici and F. Palumbo, "How to build an e-learning product: Factors for student/customer satisfaction," Bus. Horiz., vol. 56, no. 1, pp. 87-96, 2013.

[27] A. S. Wissenschaft Gesellschaft für Medien in der, Qualitätssicherung im E-Learning. Waxmann Verlag.

[28] Y.-T. Sung, K.-E. Chang, and W.-C. Yu, "Evaluating the reliability and impact of a quality assurance system for E-learning courseware," Comput. Educ., vol. 57, no. 2, pp. 1615-1627, 2011.

[29] R. J. M. Ventayen, K. L. A. Estira, M. J. De Guzman, C. M. Cabaluna, and N. N. Espinosa, "Usability Evaluation of Google Classroom: Basis for the Adaptation of GSuite E-Learning Platform," 2018

[30] M. Ouadoud, M. Y. Chkouri, and A. Nejjari, "LeaderTICE: A Platforms Recommendation System Based on a Comparative and Evaluative Study of Free E-learning Platforms," Int. J. Online Eng. IJOE, vol. 14, no. 1, pp. 132-161, 2018

[31] M. H. Dembo, Applying Educational Psychology, 5 edition. New York: Longman Pub Group, 1994.

[32] B. Khan, Managing E-Learning Strategies: Design, Delivery, Implementation and Evaluation. Information Science Publishing, 2005.

[33] S. Britain and O. Liber, "A framework for pedagogical evaluation of virtual learning environments," 2004.

[34] D. Laurillard, "A conversational framework for individual learning applied to the 'Learning Organisation' and the 'Learning Society," Syst. Res. Behav. Sci., vol. 16, no. 2, pp. 113-122, 1999.

[35] A. V. Aho and J. D. Ullman, Foundations of Computer Science: C Edition, New edition edition. New York: W. H. Freeman, 1994

$16^{\text {th }}$ LACCEI International Multi-Conference for Engineering, Education, and Technology: "Innovation in Education and Inclusion", 19-21 July 2018, Lima, Peru. 